\title{
La presencia alemana en la Ciudad de México: La firma comercial de Carlos Haghenbeck Cía. 1852-1858
}

\section{The German Presence in Mexico City: The Commercial Firm of Carlos Haghenbeck Cía. 1852-1858}

\section{María Guadalupe Carapia Medina*}

FACULTAD DE HISTORIA UMSNH

https://doi.org/10.22370/pe.2019.7.2614

\section{Resumen}

El objetivo del presente artículo tiene como finalidad analizar la presencia de un migrante procedente del estado prusiano, que vino a México en 1844, que logró establecerse como un acaudalado comerciante en la segunda mitad del siglo decimonónico, a través de redes de paisanaje y familiar que coadyuvaron en la consolidación de Carl Hypolite Haghenbeck Braunwald, en el mundo del negocio del comercio de ropa y mercería en la Ciudad de México.

Palabras clave: Migración, comercio, redes, familia, negocios.

\begin{abstract}
The purpose of this article is to analyze the presence of a migrant from the Prussian state, who came to Mexico in 1844, who managed to establish himself as a wealthy merchant in the second half of the nineteenth century, through networks of country and family who helped consolidate Carl Hypolite Haghenbeck Braunwald, in the world of the clothing and haberdashery trade business in Mexico City.
\end{abstract}

Keywords: Migration, commerce, networks, family, business.

* guadap73@hotmail.com 


\section{INTRODUCCIÓN}

a migración Europea hacía México fue un proceso creciente desde finales de la época colonial. Entre los diversos extranjeros asentados en México durante el siglo XIX, los alemanes se distinguieron por ser un grupo representante del capital comercial e industrial occidental, que sin duda aprovechó las confusas circunstancias económicas y políticas del lugar receptor, así como las oportunidades de la reorientación de la economía mundial, para generar profundas transformaciones en el patrón local de consumo; incrementando así el número de socios comerciales y modificando de manera sustancial la estructura del comercio exterior mexicano.

Las relaciones entre los Estados alemanes y México durante el siglo XIX, versa sobre los tratados comerciales, de amistad, navegación y de los proyectos de colonización, que permitieron la llegada de migrantes. Esta relación bilateral se fue incrementando conforme se desarrollaron las políticas exteriores de los gobiernos independientes mexicanos.

El espíritu burgués de Carl Hypolite Haghenbeck Braunwald, presente desde su llegada como representante -L.L. Commanditgesellschaftauf Aktienfür Fabrikation von Nähnaschienen A.G.- de la naciente fábrica de máquinas de coser, Deutsche Waffenund Munitionsfabriken (DWN). ${ }^{1}$ Le permitió obtener un conocimiento previo de las condiciones del mercado en México, y alentarlo a tomar la decisión de incursionar en el negocio de ropa y mercería. A través de sus libros de contabilidad se distingue la forma como estableció y organizo cada una de sus actividades comerciales, ningún gasto debía sería mayor a lo necesario, su prioridad acumular capital en el menor tiempo posible para recapitalizar sus negocios. ${ }^{2}$

Uno de los primero aspectos que tuvo que atender fue regularizar su situación legal en el país, en cumplimiento de la legislación mexicana a través del Reglamento de Pasaportes, Leyes y Órdenes vigentes. ${ }^{3}$ Carl Hypolite Haghenbeck Braunwald solicitó al gobierno mexicano su permanencia a través de su carta de seguridad el 27 de enero de $1844 .{ }^{4}$ Este cumplimiento tuvo que formalizado cada año 
mediante su renovación al supremo gobierno, por conducto de su agente o por la autoridad civil del lugar de residencia. ${ }^{5}$

$\mathrm{Su}$ inicio modesto, se convirtió con el paso de años como un rico comerciante, prestamistas y latifundista en la Ciudad de México. Los primeros negocios relacionados en el comercio de ropa se convirtieron en el punto de partida para alcanzar una posición prominente, por la propias condiciones que le país receptor le ofreció, y aprovechando la recuperación económica en la segunda mitad del siglo XIX, construyó toda una estructura de redes que dio lugar a una importante fortuna, los vínculos familiares y de paisanaje, fueron el eje fundamental que le aseguró el éxito pese algunos fracaso.

Los inicios en el Comercio: El Cajón de ropa "La Luz del Día” I 846 .

La carrera de Carl Hypolite Haghenbeck Braunwald, principia como pequeño comerciante, con un socio de Hamburgo. En 1846 abrió su primer negocio, llamado por aquel entonces "cajón de ropa," al que puso por nombre "La Luz del Día", ubicado en la 2a de la calle de Monterilla (hoy 5 de febrero), en el centro de la Ciudad de México. ${ }^{6}$

Para establecer el negocio de ropa se asoció con su compatriota Desebrock, su poco capital para esta actividad, obligó a Haghenbeck solicitar un préstamo por la cantidad de 10000 mil pesos, al rico comerciante Antonio C.L. Meyer Gallen, un alemán naturalizado mexicano, venido a tierras mexicanas en 1828 para establecer un almacén de ropa, sus buenos resultados le permitieron -años más tarde-presentarse como fiador, prestamista y apoderado de importantes casas de comercio como Dunlop y Cía. Mon-Marshall, Francisco Schneider y Cía. ${ }^{7}$

El contrato celebrado el 25 de julio de 1846, ante la notaría 169 administrada por Ramón de la Cueva en la Ciudad de México, define los términos del contrato, a través de su apoderado legal de esos momentos, Don Federico Hube. El préstamo fue acordado por cinco años, Meyer entregó el capital en una sola exhibición en plata 
fuerte de cuño corriente, con una tasa preferencial de interés del $6 \%$ anual en la misma moneda. El atraso en algún pago, causaría un interés sobre el mismo, en las últimas cláusulas se puntualiza que en caso de no cumplir la deuda se reintegraría con el giro comercial de ropa al menudeo, con todas las mejoras que obtuviera. ${ }^{8}$

La moción de establecer este tipo de negocio en un contexto de mercado con gran demanda, coadyuvaría a consolidar los resultados de éxito según la "mentalidad calculadora" de Haghenbeck. ${ }^{9}$ Pero desatendió la situación del conflicto existente entre México y los Estados Unidos, la incertidumbre de condiciones de inestabilidad política por el conflicto disminuyó de forma notable el comercio en los principales puertos, a causa del bloqueo de los norteamericanos, limitando la importación de bienes a través de ellos. La derrota de varias ciudades del país permitió el aumento del contrabando, quedando involucradas las grandes casas comerciales. ${ }^{10}$

La invasión norteamericana afectó las condiciones políticas, económicas y sociales, dejando un país desolado y desmoralizado por todos los espacios del territorio. El desastre fiscal no se detuvo, ya que el bloqueo de los puertos no solo hizo imposible la importación de las mercancías, también condicionó el cobro de los aranceles en las aduanas, principal fuente de ingresos del gobierno mexicano. Éste dejó de obtener alrededor de la mitad de sus ingresos regulares, en la coyuntura donde más lo necesitaba. La paralización del comercio perjudicó la economía del país, al igual que a los comerciantes que vivían -principalmente- del comercio exterior; aunque se pudo importar por puertos pequeńos, la mayor parte del comercio se realizó a través de los puertos controlados por las tropas norteamericanas. ${ }^{11}$

Este contexto dificulto el escenario del negocio, seguido por la salida imprevista de su socio Desebrock quien retiro su inversión legando la administración y compromisos devengados a su socio. Comprometiendo Haghenbeck a renegociar la deuda con Meyer por dos año más que finalmente saldó en 1853. Los libros de contabilidad del cajón de ropa "La Luz del Día" exponen las bajas ventas que condicionaron el éxito del mismo. No obstante para 
1849 se distingue cierta bonanza, Haghenbeck establece relación laboral con los hermanos Leopoldo y Eduardo Daus, provenientes de una casa de comercio importante de Hamburgo, relacionado con la venta de mercería y propietarios de un cajón en la Ciudad de México, fueron contratados por Carl para realizar negocios a su nombre y servir como apoderados legales. ${ }^{12}$ Por su parte Haghenbeck aparece para 1850 como fiador del cajón de mercería de los Daus. ${ }^{13}$

Estos hechos, ayudan a entender las maneras y condiciones bajo las cuales Haghenbeck, va estableciendo sus redes dentro de grupo de alemanes en este primer momento, esenciales para la consolidación de sus negocios de comercio, préstamos y tierras. La reciprocidad fue un factor determinante para alcanzar la estabilidad, el crecimiento y el afianzamiento dentro del grupo de alemanes que privilegiando las redes de paisanaje en la tierra receptora.

El cajón de ropa "La Luz del Día”, se sumó a esa gran cantidad de espacios comerciales al menudeo. A diferencia de los grandes almacenes ligados al comercio de importación a gran escala, estos pequeños negocios dependieron de la compra de mercancías a las casas de comercio, a través de servicios de crédito. La actividad comercial del prusiano plasmada en su libreta de abonos, ponen a la vista el tipo de mercancía que comerciaba, los costos, los clientes y las formas de pago, que en conjunto expresan las prácticas de comercio de Haghenbeck, en la Ciudad de México.

La mayor parte del comercio de su cajón de ropa se realizó a través de venta en abonos, por acuerdo oral se enunciaba el monto de los pagos y el tiempo de crédito de las mercancías, en un cuaderno se registró por día, mes y año cada uno de los abonos que los clientes depositaban a su deuda, una vez saldada se marcó con acotaciones, de forma conjunta también efectuó ventas de pago directo en menor cuantía. ${ }^{14}$ El entregar mercancía de esta forma pone de manifiesto el fin de lograr mayores ganancias, porque una parte de las mercancías ofrecidas en su negocio las adquiría bajo la modalidad de efectos por comisión, (adición del precio de mercancías y el interés del crédito). ${ }^{15}$

La relación con Antonio Meyer y Enrique Pagenhardt, habla 
de una correspondencia articulada, en respuesta a las situaciones de intereses de orden económico. Los alemanes consolidados en tierras mexicanas adjudicaron empréstitos a Carl, y al mismo tiempo fueron los proveedores de las mercancías que vendía en el cajón de ropa, tomando en cuenta su presencia como propietarios de casas comerciales en el Puerto de Veracruz.

\section{TABLA I.}

Mercancia que ofertaba del Cajón de ropa “la luz del día”

\begin{tabular}{|l|c|}
\hline \multicolumn{1}{|c|}{ MERCANCIA } & PRECIO (PESOS) \\
\hline Félpalos de seda & 10 \\
\hline Frazadas & 4 \\
\hline Guantes & 1.2 \\
\hline Guantes con adorno & 3 \\
\hline Sombrillas & 10 \\
\hline Calcetines & 1.2 \\
\hline Corbatas & 1.1 \\
\hline Cortes de tarlatana & 7 \\
\hline Chalecos & 2 \\
\hline Mantillas & 1.60 \\
\hline Cortes de pantalón casimir & 6 y7 \\
\hline Cortes de pantalón doble & 1.95 \\
\hline Servilletas & 1.6 \\
\hline Medias de seda y algodón & 2.7 \\
\hline Chales de terciopelo & 10 \\
\hline Piezas de Bretańa & 4.4 \\
\hline Mascadas & 3 \\
\hline Camisas & 4 \\
\hline Muselina & .75 \\
\hline Piezas de Hamburgo & 1.4 \\
\hline Piezas de Bretańa & 1.2 \\
\hline Gramo de oro & 16 \\
\hline Zapatitos & 1 \\
\hline
\end{tabular}

Tabla elaborada a partir de la información obtenida en APMCBFAHDL. Libro de Contabilidad, La Luz del Día, 1849 
Los clientes frecuentes de Haghenbeck, fueron mujeres y varones de la clase media y alta de la Ciudad de México, considerando algunos apellidos de la época, en un contexto donde la población pudiente atendía estar a la moda para asistir a sus eventos sociales, participar en ceremonias religiosas, acudir a la ópera y reuniones de negocios, haciendo gala de su elegancia. Atendiendo la competencia de otros giros comerciales -incluidas las alemanas, las inglesas, las mexicanas y las francesas (las más demandadas) que monopolizaron el giro del comercio de ropa y novedades. ${ }^{16}$ Esta situación obligo a Carl dar la debida la atención para el buen funcionamiento de su cajón de ropa, y hacerlo visible en ese piélago de comercio.

En cierta medida logró su intención, la lista de clientes frecuentes aumentaron y donde figuran personas de renombre en la Ciudad de México, José María Anzorena, Francisco Bocanegra, Loreto Hizalturri, Loreto Rodríguez, Miguel Cervantes, Jesús Zúñiga, Antonio Mesa, José María Valdez, Josefa Rodríguez, Antonio Leal, Manuel Alegre, la Sra. Manríquez, Ramón Ortiz, la Sra. Lozano, Guadalupe Marmolejo, Dolores Avendaño, Juliana Rea, la Sra. Flores, Germán Landa y el sacerdote Cadena. ${ }^{17}$

La situación de las ventas como todo negocio tuvo variaciones, la gran incertidumbre, la situación política-económica, la competitividad en el comercio minorista y de los grandes almacenes, determinaron las altas y bajas ventas del cajón de ropa "La Luz del Día”. Algunas referencias de ingresos por venta de ciertos días, permiten visibilizar un parte de la actividad comercial de Haghenbeck, con una media de 117.06 peso y un ingreso mensual de 2,809.6 pesos de acuerdo a las referencia de la tabla, el cual pudo ser mayor teniendo en cuenta los días sin referencia de costes. 
TABla 2. IngResos POR VENTAS DEL MES DE MAYO DE I849 "CAJÓN DE ROPA “LA LUZ DEL DÍA”

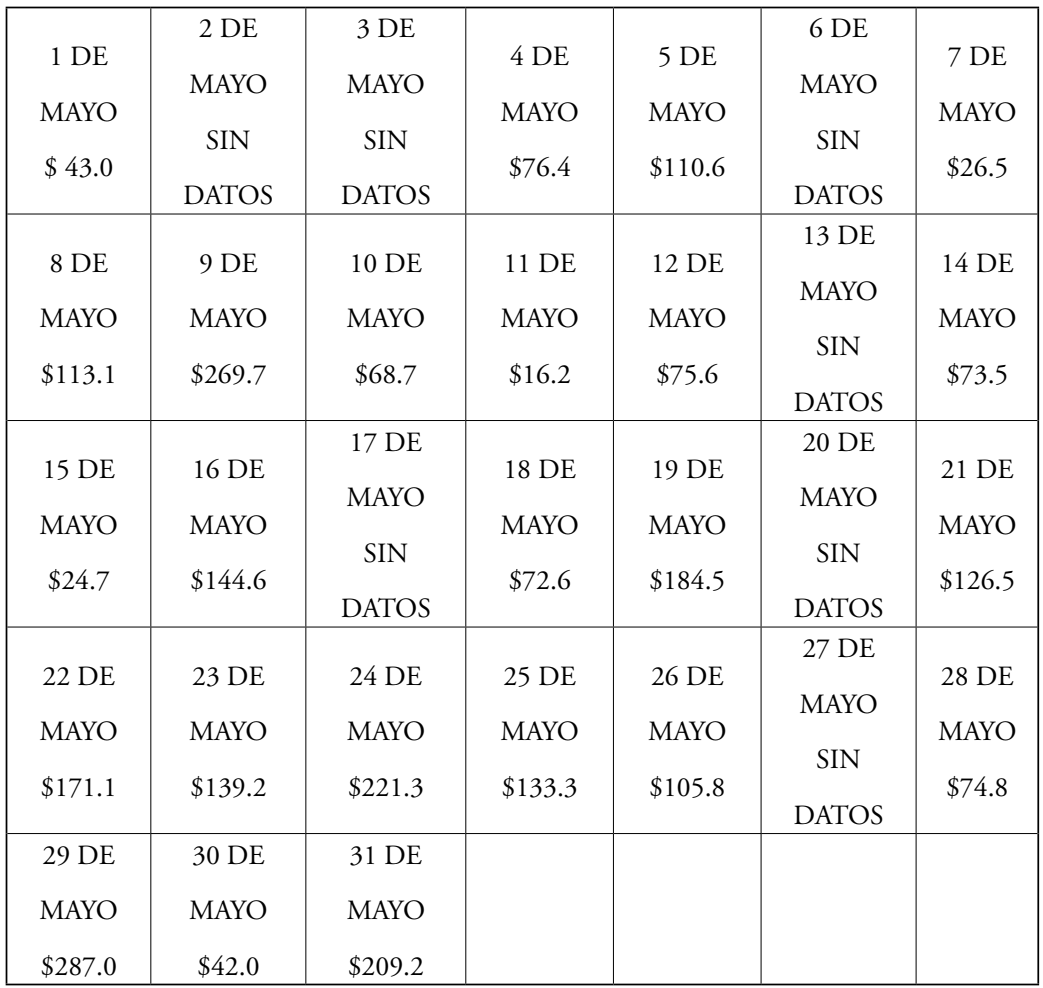

Tabla elaborada a partir de la información obtenida APMCBFAHDL. Libro de Contabilidad, La Luz del Día, 1849.

El interés de alcanzar su consolidación de comerciante Haghenbeck, negocio un segundo préstamo en 1850 con su compatriota Enrique Pagenhardt, por la cantidad de 12 mil pesos por nueve meses, con una tasa preferencial de $6 \%$ anual, con los intereses respectivos por demora de cada uno de los pagos convenidos y firmados ante notario público por los interesados. ${ }^{18}$

Las condiciones de obtención de crédito dan cuenta de relaciones de paisanaje en los negocios, adquirieron una gran relevancia para el prusiano fuera del lugar de origen, y reitera la intención de integrarse al grupo de alemanes exitosos en México. En esa construcción de 
redes se alcanza a distinguir otras circunstanciales referentes a las establecidas por Pagenhardt, ligado comerciante alemán Adolfo Heymel y el hijo del mineralogista alemán y director de la Mexican Company en Oaxaca, Uslar, asociados en Pagenhardt, Uslar Heymel y Cía. ${ }^{19}$

Los inicios de 1850 presentaba un escenario promisorio, la recesión económica a causa del problema con los Estados Unidos transitaba, pero las pugnas políticas entre los gobiernos centralistas representados por Santa Anna y de liberales como Álvarez, Comonfort y Juárez formaron una situación de claro -obscuros para el país. Un Plan de Ayutla que arremetió contra la dictadura de Antonio López de Santa Ana, respaldado por Juan N. Álvarez e Ignacio Comonfort, una nueva Constitución en 1857 que incorpora la Ley Juárez, La Ley Lerdo y La Ley Iglesias al rango constitucional, una Ley de Nacionalización de bienes eclesiásticos en 1859, pulsaron la historia de la segunda mitad del siglo XIX. ${ }^{20}$

\section{La firma Carlos Haghenbeck y Cía. I 852}

La relaciones entre los comerciantes Antonio Meyer y Teodoro Barhe, permitió establecer un acercamiento con Haghenbeck para hacer negocios, una distinción gratificante en su propósito de consolidación y residencia en el país para su persona. Una vez de extensas conversaciones se acordó organizar una compañía en 1852 con el nombre Carlos Haghenbeck y Cía. Con esta sociedad se establecía un almacén de ropa y mercería bajo el nombre "La Mina de Oro" ubicado en la calle Cadena número 2, (hoy Venustiano Carranza) en el centro de la Ciudad de México. ${ }^{21}$

El conjunto de recursos, bienes y valores disponibles para establecer la compañía para llevar la actividad comercial, ascendió a la cantidad de 120.000 pesos; para el proyecto, Barhe depositó $\$ 100000$ pesos provenientes de sus negocios de Guadalajara y Veracruz, 30 mil pesos por cada uno de ellos y 40 mil del almacén de la Ciudad de México. Por su parte, Carl Hypolite Haghenbeck Braunwald aportó 20 mil en especie (el cajón de ropa "La Luz del Día”). La compañía fue acordada por cinco años, además, se estipuló 
que el giro quedaría sobre comisiones, efectos en consignación y adelantos, compra de efectos en Europa, cobros de libranzas en comisión y entrega de créditos, que permitieran reducir los riegos de una posible quiebra. ${ }^{22}$

El cajón de ropa de Haghenbeck se incorporó de manera similar como otros establecimientos comerciales de México y América Latina. Las pequeńas tiendas se transformaron en grandes almacenes comerciales, a través de inversión de capitales y un con un complejo proceso de diversificación de actividades. ${ }^{23}$

Las cláusulas del convenio establecieron pagar el 6\% anual por intereses al capital aportado por Barhe a la compañía. Las ganancias obtenidas por el almacén "La Mina de Oro" se distribuirían el $40 \%$ para el socio mayoritario y el $60 \%$ para el administrador de la compañía, (socio industrial). Con este nombramiento, Haghenbeck ocupó el puesto de importancia en términos administrativo, porque se encargaría de las compras de mercancías, hacer las ventas, llevar la contabilidad y contratar personal, de las inversiones, realizar los pagos de derechos comerciales y de transporte, asimismo se le obligo a vivir en la Ciudad de México donde se encontraba la casa comercial y se le prohibió hacer todo negocio particular, ya que sus obligaciones eran exclusivas para la compañía. Como socio capitalista, Teodoro Barhe tuvo el derecho de hacer negocios propios sin ningún problema y tener su residencia donde conviniera a sus intereses, al no tener ninguna obligación administrativa. En relación a las ganancias, la cláusula especifica que para no descapitalizar a la compañía, cada uno de los socios solo podría retirar de manera anual 5000 pesos, las ganancias restantes serían integradas al capital de créditos y adquisición de mercancías de la casa comercial. ${ }^{24}$

En la estructura jerárquica en último peldaño se ubicó el socio capitalista en su ausencia el representante de la firma y los apoderados legales, seguidos por los socios los socios industriales y en tercer lugar los dependientes y empleados. ${ }^{25} \mathrm{El}$ cargo desempeñado por Haghenbeck en la compañía lo obligo a utilizar su experiencia de comerciante, pero al mismo tiempo le dio la oportunidad de obtener nuevos conocimientos del negocio fundamentales al momento de 
retirarse de la asociación con Barhe, y la posibilidad de relacionarse con importantes casas comerciales de México, Inglaterra, Francia y Alemania, significativas para extender sus redes de negocios para la importación de mercancías como lo hacen ver la facturas de comercio para los años de $1860 .^{26}$

El socio capitalista de Carl Hypolite Haghenbeck Braunwald, figuró como un importante comerciante, minero y prestamista representante desde 1820 de la Preusische Seehandlung, compañía mercantil oficial de Prusia, hijo de un importante comerciante de Hamburgo, vinculado al comercio entre México y las ciudades hanseáticas (Bremen, Hamburgo y Lübeck), junto a su hermano -Adolfo Barhe-, representó los intereses de la familia en México, por su parte el hermano Federico, socio de Carlos Unthoff, poseyó la casa Barhe \& Unthoff en Veracruz representado por Rodolfo Meyer. ${ }^{27}$

Las inversiones de Barhe cruzaron el comercio de ropa y mercería, sus intereses también se encontraron en el sector minero, como lo cita Mentz, al lado de Pérez Gálvez, Mackntosch, Rosas, Sánchez Navarro, Farías y otros socios menores, participó como accionista del Mineral del Catorce, (cuya acción, tenía un valor de 10000 pesos). El buen paso de sus negocios permitió a Teodoro Bahre regresar Hamburgo prospero, en su figura se expresó el arquetipo de extranjero que llegó a México a hacer fortuna rápida y retornar a su lugar de origen a disfrutar de sus ganancias. Para vigilar sus intereses, envió a México a su hermano Christian, con la encomienda de administrar sus negocios y las firmas comerciales Bahre, Lemmen y Cía. en la Ciudad de México, Guadalajara y Veracruz.

El almacén "La Mina de Oro", de manera habitual abría sus puertas a las siete de la mañana y las cerraban hasta las diez de la noche, todos los días del año con excepción de los días festivos, como lo hacían los otros comercios. Participó en las llamadas ventas especiales, donde se ofrecía mercancías a bajo costo y eran aprovechadas por sus clientes. ${ }^{28} \mathrm{La}$ ubicación en las calles céntricas de la Ciudad de México lindante al conjunto de casas comerciales establecidas daba lugar a figurar en el boceto del comercio, ocupando 
una casa de origen colonial de dos plantas, en la primera se ubicó la tienda y en la parte alta fue destinada como bodega de resguardo de mercancías, el negocio se distinguió por la venta de ropa y mercería de importación a través de ventas al contado en efectivo, pero también se utilizó el crédito a medianos y pequeños comerciantes por medio letras de cambio como un medio de respaldar las ventas a plazos. ${ }^{29}$

El crédito le permitió desplazar las mercancías hacia otros comercio en la capital del país y la provincia, ofreció a sus clientes un extenso surtido de ropa, telas, mercería y sedería de distintas calidades: de lujo, medio lujo y sencilla. Las consideraciones comerciales que en su momento se establecieron en una situación de confianza, se transformaron -muchas de las veces- en conflictos legales entre el proveedor y el cliente, por el incumplimiento de los plazos establecidos entre los contrayentes, que implicó costos y largos procesos legales. ${ }^{30}$

Pronto el almacén "La Mina de Oro", despuntó por su comercio al mayoreo de diversos tipos de mercancías provenientes de Europa. Ello implicó subrogar diferentes costos de transacción y embalaje en los puertos, principalmente en el de Veracruz, que de acuerdo a la cantidad y tipo de mercancías que se adquirían, solicitaba pagos por concepto de aduana (6 pesos), flete $(32.71 / 2)$, papel sellado $(2.4$ pesos), empaque (15 pesos), derechos de consumo (23.6 pesos), comisión (12 pesos), importación (100.7) y gastos de expedición (41.2). Evidentemente todos estos gastos se verían reflejados en los precios de las mercancías comercializadas en la ciudad de México, lo que fue atenuado con las estrategias de crédito en su comercio. ${ }^{31}$

Teodoro Bahre hizo valer su posición de socio capitalista y exigió a Haghenbeck, adquirir mercancías de su casa comercial en Veracruz, Bahre \& Uhthoff, por la cantidad de 547.6 pesos. ${ }^{32}$ Otras mercancías fueron adquiridas a través del comercio con Liverpool, por un monto de 13315 pesos con un pago de contado de 430.24 pesos y una deuda de 907.38 pesos, a un $12 \%$ anual, entre las mercancía destacan (36 piezas de pana, 18 de panillas y 13 casimires, 10 docenas de camisa interior, 50 piezas de mantillas, 100 piezas de 
muselinas, 14 piezas de lencería). Además adquirió en mercancía a la casa comercial Baring Brother Cía. de Londres, por la cantidad de 1000 pesos. ${ }^{33}$

Uno de los socios con más presencia en la relaciones de comercio con la compañía Carlos Haghenbeck Cía. Estuvo representada por la compañía de Guillermo O. Brienm de París, quien en el mes de noviembre de 1852 -vía Havre- a Veracruz, por el barco Amelia, comercio dos cajas de tapalos de lana, guantes y pecheras, con un costo de 3866.10 pesos. ${ }^{34}$ Las compañías Liebert de Manchester, por la cantidad de 4950 pesos; L. Henry Cía, Gorrifeen Cía, 450 pesos; H.C. Back, 4098.7 pesos y Corrady Müller, 1995 pesos, importados también por el puerto de Veracruz. ${ }^{35}$

Los datos citados permiten reconstruir las relaciones de comercio, establecidas por la compañía desde México y las casas mercantiles de Europa, y dan cuenta del dinamismo comercial que alcanzo la compañía de los socios Barhe-Haghenbeck y formando parte de las estadísticas de las importaciones mercantiles realizadas por los compañías comerciales alemanas en México, que ascendieron a 11 804009 pesos. $^{36}$

El uso de libranzas fue un uso común en las relaciones comerciales, los créditos estuvieron al orden de día ante la falta de moneda circulante y la inseguridad en los caminos que hicieron difícil el envío y el transporte de dinero en efectivo. Las enormes distancias de las plazas de comercio, autorizo a la libranza para ser aceptada como medio de pago en el negocios de Carlos Haghenbeck y Cía. con un rédito del $9 \%$ anual del valor, generalmente, la libranza fue a favor de otro comerciante y comenzaba a correr desde el día de su aceptación. ${ }^{37}$

Las libranzas circularon como garantía de crédito, este tipo de documentos dan cuenta de la fecha, cantidad, época de pago, lugar donde debía realizarse, el nombre de la persona a cuya orden se debía hacer la liquidación, el origen y especie de valor que representaba, además de los datos de nombre y domicilio de la persona sobre quien estaba la libranza, así como las firmas del librancista, el libratorio y el mandatario. ${ }^{38}$ Una medida que facilitó el pago ante la falta de un 
sistema bancario, esta modalidad crediticia fue una opción posible y confiable en las relaciones comerciales, como un tipo de documento mercantil que se usó en México durante el siglo XIX. ${ }^{39}$

Tabla. 3 LibranZas de Carlos Haghenebeck CÍA.

\begin{tabular}{|c|l|l|c|l|}
\hline NOMBRE & $\begin{array}{c}\text { FECHA DE } \\
\text { LIBRANZA }\end{array}$ & CANTIDAD & $\begin{array}{c}\text { TIEMPO DE } \\
\text { LIBRANZA }\end{array}$ & RÉDITOS \\
\hline Rafael Cansina & 15 de octubre & $\$ 6,635.3$ & 75 días & $\$ 124.3$ \\
\hline Rafael Cansina & 15 de noviembre & $\$ 6,691$ & 106 días & $\$ 177.2$ \\
\hline Rafael Cansina & 15 de diciembre & $\$ 6,754.7$ & 136 días & $\$ 229.5$ \\
\hline Jecker Torres Cía. & 11 de septiembre & $\$ 8,180$ & 43 días & $\$ 83.7$ \\
\hline Jecker Torres Cía. & 11 de octubre & $\$ 8,240$ & 71 días & $\$ 146.1$ \\
\hline Beistegui & 7 de noviembre & $\$ 5,150$ & 98 días & $\$ 126$. \\
\hline Total & & $\$ 41,651$ & & $\$ 887.2$ \\
\hline
\end{tabular}

Tabla elaborada a partir de la información obtenida en APMCBFAHDL, Libro de contabilidad Carlos Haghenbeck y Cía. 1852-1856, f. 1.

La compañía realizó actividades por comisiones y efectos en consignación y adelantos. ${ }^{40}$ "La Mina de Oro" no se limitó a distribuir y ofertar mercancía de manera exclusiva de casas comerciales alemanas, el comercio del almacén ofreció mercancías inglesas, francesas y todo aquel que pudiera generar ganancia. ${ }^{41}$ Entre los deudores de Carlos Haghenbeck y Cía., por este tipo de operaciones, encontramos a Gamio Domeneq, con varios contratos en el mes de noviembre de 1852, por la cantidad de 22500.00 pesos. $^{42}$

Como toda compañía, adquirió deudas para cumplir con sus operaciones comerciales. Los proveedores entregaron créditos a Carlos Haghenbeck y Cía., de mayor volumen, dado el limitado efectivo y las ventas que realizó (libranzas), se vio obligado a depender -hasta cierto punto- del crédito comercial para efectuar compras de una manera más regular, algunas deudas contraídas por la compañía, entre los meses de noviembre y diciembre de 1852, ascendieron a los 76576.92 pesos. $^{43}$ 
Tabla 4. Cuentas de caja de “la mina de oro” i 856 -i 858

\begin{tabular}{|c|c|c|c|}
\hline FECHA & INGRESOS & FECHA & INGRESOS \\
\hline Noviembre de 1856 & $\$ 177,548.2$ & Enero de 1858 & $\$ 29,515.6$ \\
\hline Diciembre de 1856 & $\$ 244,322.17$ & Febrero de 1858 & $\$ 24,938.7$ \\
\hline Enero de 1857 & $\$ 139,883.6$ & Marzo 1858 & $\$ 20,914.1$ \\
\hline Febrero de 1857 & $\$ 245,714.1$ & Abril de 1858 & $\$ 59,925.6$ \\
\hline Marzo de 1857 & $\$ 139,970.3$ & Mayo de 1858 & $\$ 59,827.1$ \\
\hline Abril de 1857 & $\$ 92,877.4$ & Junio de 1858 & $\$ 2,814.4$ \\
\hline Mayo de 1857 & $\$ 182,986.4$ & Julio de 1858 & $\$ 2,754.7$ \\
\hline Junio de 1857 & $\$ 96,906.6$ & Agosto de 1858 & $\$ 8,776.4$ \\
\hline Julio de 1857 & $\$ 96,906.6$ & Septiembre de 1858 & $\$ 11,195.3$ \\
\hline Agosto de 1857 & $\$ 154,333.6$ & Octubre de 1858 & $\$ 12,245.6$ \\
\hline Septiembre de 1857 & $\$ 60,348.6$ & Noviembre de 1858 & $\$ 11,829.3$ \\
\hline Octubre de 1857 & $\$ 46,492.2$ & Diciembre de 1858 & $\$ 16,464.3$ \\
\hline Noviembre de 1857 & $\$ 34,507.5$ & & \\
\hline Diciembre de 1857 & $\$ 40,252.3$ & & \\
\hline
\end{tabular}

Tabla elaborada a partir de la información del APMCBFAHDL, Libro Almacén La Mina de Oro 1856-1858, fs. 3-28.

La diversidad de las actividades de Carlos Haghenbeck y Cía., incluyó utilizar parte de sus ganancias en el negocio de escrituras vencidas de arrendamiento de casas en contrato directo y otras en el mercado de documentos. En su mayoría fueron pagados, en otros casos se tuvo que hacer usos de abogados para hacer cumplir los documentos firmados. Además de préstamos hipotecarios que se realizaron con la entrega de escrituras como garantía. ${ }^{44}$

La importancia de sus matrimonios con Juliana y Josefa Sanromán, en 1850 y 1856, ayudará a la consolidación de sus negocios, y estrechará las relaciones familiares con su suegro Blas Sanromán, rico comerciante de la Ciudad de México. La elección de sus esposas dentro de un círculo social importante, le significó emparentar con señoritas de buena cuna, educadas y acaudaladas. La red familiar representado por sus esposas Juliana San Román Castillo y Josefa San Román Castillo, fue relevante porque le permitió entrar a su círculo e incorporase al escenario de las familias de prestigio de la gran Ciudad de México que guardaban cierto control administrativo, político y económico. ${ }^{45}$ 
A partir de los matrimonios, sus alianzas se extendieron con el apoyo de don José María Blas Sanromán Gómez originario de Santa María de los Lagos Moreno de la Nueva Galicia, quien años más tarde emigró a la Ciudad de México con su familia para establecer sus negocios comerciales, su bonaza lo hace figurar entre los principales e importantes negociantes y vinculado con el grupo de comerciantes, mineros y latifundistas mexicanos. ${ }^{46} \mathrm{~A}$ partir de estos matrimonios aseguró su condición de extranjero y su presencia en el comercio a través de la actividad comercial de su suegro.

El respaldo de la familia fue fundamental en los momentos que las relaciones con su socio de la compañía no marchaban del todo bien, los intereses e ideas de cada uno de ellos fueron afectando y desgastando la situación. La intervención de Barhe, para imponer su condición de socio mayoritario y exigir sus voluntades fuera de los términos del convenio firmado, influyó para dar por terminada la relación de comercio de la compañía, quedando sin efecto sus operaciones. El patrimonio social se volvió necesario para el pago de acreedores y se generó el derecho a recibir la parte correspondiente del remate de la negociación.

La nota publicada en febrero de 1856, en el periódico El Siglo $X I X$, cita que habiendo sido enajenada la negociación conocida como "La Mina de Oro", situada en los bajos de la casa número 1 de la $2^{\text {a }}$ calle de la Monterilla, se informa a todas la personas que tuvieran cuentas pendientes con el almacén, se presentaran dentro de los 30 días siguientes, para recibir el importe que se les adeuda; asimismo, se solicitaba a los deudores de la negociación, hacer los pagos en la casa ubicada en la calle Cadena número $21 .{ }^{47}$

Esta etapa de socio industrial llegó a su fin, y dio paso a una nueva etapa en la vida económica del alemán. De forma individual inicia sus propios negocios a partir de 1857, se dedicó de lleno a la compra de bienes raíces, ofrecer préstamos hipotecarios, al comercio de ropa, mercería y muebles al mayoreo. Finalmente Carl Hypolite Haghenbeck iría en acenso en las siguientes décadas del siglo XIX.

A manera de conclusión podemos citar que la llegada de migrantes alemanes a México, tuvo un efecto positivo en la 
construcción de un sistema de mercado nacional. En el caso de Carl Hypolite Haghenbeck Braunwald, queda claro que desde la instauración de su primer cajón de ropa, consolidó sus negocios a través del comercio, pero un factor muy importante en su despegue como empresario mayor, fue la asociación con sus paisanos, Teodoro Bahre, de quienes obtuvo inversiones de capital que a la postre, le permitieron emprender por cuenta propia, múltiples transacciones desde la ciudad de México; ciudad que utilizó como punto de distribución de mercancías de ropa y mercería, a distintos puntos comerciales del centro, occidente y norte del país. Sus ventas, fueron acompańadas por operaciones de crédito al consumo y de préstamos en moneda circulante.

Con las redes de paisanaje y de familia, el alemán prusiano entendió de manera adecuada, que el comercio nacional e internacional era más rentable y desde donde podía llevar a cabo una mayor y una más rápida acumulación. Las redes se extendieron hacia casas comerciales europeas, que a su vez otorgaron préstamos de créditos, a los establecimientos comerciales e industriales de alemanes radicados en la ciudad de México. Haghenbeck logró como agente comercial, obtener un capital que le permitió independizarse, fundar nuevos negocios y comprar un número importante de propiedades en diversos puntos de México.

\section{Archivos}

APMCBFAHDL (Archivo Particular Museo Casa de la Bola "Fundación Antonio Haghenbeck de la Lama IAP.) AGNCDMX (Archivo General de Notaria de la Ciudad de México). AGN (Archivo General de la Nación).

\section{Hemerografica}

Periódico Siglo XIX

REVISTAS

BERNECKER, W. (1993). "Contrabando. Ilegalidad y corrupción en el México decimonónico" en Espacio, Tiempo y Forma, Serie V, Historia Contemporánea, t.6. 
Bibliografía

ABASCAL ZAMORA. (I991). "Pasado, presente y futuro de los títulos de valor", en Centenario del código de comercio, México, Instituto de Investigaciones Jurídicas - Universidad Nacional Autónoma de México.

BERNECKER, W. (2001). "Las relaciones comerciales germanomexicanas en el siglo XIX” en BIEBER, L.E. (Coord.) Las relaciones germano-mexicanas desde el aporte de los hermanos Humboldt hasta el presente. México: El Colegio de México.

BERNECKER, W. (2005), Alemania y México Alemania y México en el siglo XIX, México, Facultad de Filosofía y Letras UNAM/ El Colegio de México. Servicio Alemán de Intercambio Académico.

BERNINGER DIETER (I974), La inmigración en México 18211857, México, SEP/Setentas.

DUBLÁN, M. y LOZANO, J.M. (1876) (compiladores). Legislación mexicana ó colección completa de las disposiciones legislativas expedidas desde la independencia de la República, ordenada (...) México: Imprenta de Comercio, vol. IV.

FLORES CABALLERO. (2014). Administración y politica en la historia de México, España, S.L. Fondo de Cultura Económica de España.

GAMBOA OJEDA, (2009). Los barcelonnetes en México, miradas regionales, siglo $X I X-X X$. México, Benemérita Universidad de Puebla.

GUARDINO. P. (2018). La marcha fúnebre. Una historia de la guerra entre México y Estados Unidos, trad. Mauricio Zamudio Vega, México, Grano de Sal/UNAM.

MEYER. J. (20 I I). Dos siglos, dos naciones: México y Francia 18102010, México, CIDE.

METZ VON. (1982), Los pioneros del imperialismo alemán en México, México, CIESAS.

NAVARRO ZAMORANO. (1866), Las letras de cambio. Libranzas, vales, pagares o billetes a la orden. $Y$ cartas órdenes de crédito, México, Imprenta de Abram Gonzáles. 
ORTEGA R Y PÉREZ GALLARDO. (1902), Estudios genealógicos, México, Imprenta de Eduardo Dublán.

QUINTANA ADRIANO, (2005), Evolución histórica mercantil 1325-2005, México, Porrua-UNAM, Instituto de Investigaciones Jurídicas.

RABADÁN FIGUEROA. (2006). Propios y extraños: la presencia de los extranjeros en la Ciudad de México, 1821-1860, México, Universidad Autónoma de Morelos/Miguel Porrúa.

SOMBART W. (1979). El burgués, Madrid, Alianza Editorial.

TANENBAUM. (1985). México en la época de los agiotistas, 18211857, México, Fondo de Cultura Económica.

\section{DIGITALES}

La fundación Cultural Antonio Haghenbeck y de Lama, I.A.P,” Diario Digital, Cultura UNAM, www.museosdemexico.org [Consulta 20 de agosto de 2014.

\section{Notas al final}

${ }^{1}$ Mentz, Los pioneros del imperialismo, p.101. APMCBFAHDL, Familia, carpeta. 001, f. s/n. En este un documento cita que vino a México sirviendo en un buque. Las peculiaridades manifiestas del personaje, hacen evidente una notoria experiencia en el mundo de los negocios que deroga la segunda referencia.

2 Sombart, El burgués, p.141, 207-208. El autor define "espíritu burgués", como virtudes en el sentido de principios (conjunto de comportamientos y actitudes determinadas), que constituyen la esencia de todo hombre de negocios, en otros términos, de todo empresario capitalista: agudo, especulador, perspicaz, ingenioso, con dotes intelectuales y capacidad en la administración.

${ }^{3}$ Rabadán Figueroa, Propios y extraños, pp. 26-28. Dublán, LoZANo, Legislación Mexicana, pp. 332, 634-638. Fue el medio a través del cual se trató de controlar la migración y evitar la introducción al territorio de extranjeros no deseables, considerados perjudiciales para el orden público y la sociedad (vaga y criminal). Las autoridades 
pretendían tener un control de la llegada de extranjeros al territorio mexicano, a través de la expedición de la carta de seguridad, para evitar inconvenientes posibles e innecesarios que pudieran generar conflictos internos y consulares. A través de la legislación, el supremo gobierno expidió pasaportes e hizo salir del territorio de la República a cualquier extranjero no naturalizado cuya permanencia fuera perjudicial al orden público, aun cuando se haya introducido y establecido con las reglas prescritas en las leyes.

${ }^{4}$ AGN, Gobernación, Cartas de Seguridad, Vol. 36, Expediente 103, 1844, f. 97. El documento hace constar que es súbdito de "la ilustrísima majestad rey de Prusia”, y a través de su representante, el infrascrito encargado de los negocios de Prusia, solicita a las autoridades mexicanas el permiso correspondiente para que se le autorice establecerse en el territorio. El documento da cuenta de "un hombre de 31 años de edad, de tez blanca, de estatura de 5', 6', ojos pardos, nariz regular, pelo castaño y barba oscura, sin ninguna seña particular.

${ }^{5}$ AGN, Gobernación, Cartas de Seguridad, Vol. 2016, Expediente 39,1860, f.2.

${ }^{6}$ Mentz, Los pioneros del imperialismo, p. 474. Dublán, Lozano, Legislación Mexicana, pp. 571-572. El decreto del 23 de septiembre de 1843, emitido por el gobierno de Santa Anna, en el artículo 2o prohíbe el comercio al menudeo para los extranjeros, a excepción de los naturalizados mexicanos, los casados con mexicanas y los residentes en el país con sus familia.

${ }^{7}$ Mentz, Los pioneros del imperialismo, pp. 458-460.

${ }^{8}$ AGNCDMX, Ramón de la Cueva, Notaria 169, Vol. 1005, 1846, f. 551.

${ }^{9}$ Por mentalidad calculadora, debemos entender la tendencia, el hábito, la facultad, de reducir el mundo a cifras y ordenar éstas en un complejo sistema de gastos e ingresos. Sombart, El burgués, p. 137.

${ }^{10}$ Bernecker, "Contrabando. Ilegalidad y corrupción”, pp. 401403. Los alemanes parecen haber practicado el contrabando, principalmente, en Colima; los mexicanos y españoles, en Tampico y Veracruz. Los puntos por donde cada uno de estos extranjeros introducían sus mercancías de manera ilegal, sin pagar aranceles en las aduanas mexicanas. La costa del Pacífico fue articulada por varias casas co- 
merciales, entre ellas la Hispano-Mexicana, la empresa Echegure, la casa peruana Sarmiento y la casa inglesa Barron \& Forbes; lo notable de estos datos, es advertir el cómo estas casas de comercio estuvieron vinculadas a personajes que estaban al frente de los consulados, como fue el caso de Echegure, que ejercía el consulado español, Barron el inglés, Forbes el estadunidense y el chileno; esto significa que aprovecharon su condición consular, exigiendo exoneración diplomática. Asimismo, hicieron uso de manera impúdica de sus diversas relaciones sociales.

${ }^{11}$ Guardino, La marcha fúnebre, pp. 200, 206, 207. Tanenbaum, México en la época, p.102. La autora señala que la creación de grupos de interés organizados, fue una limitante para el desarrollo del país. El grupo liberal especializado en los temas económicos y fiscales, estuvo a favor de las reducciones de las tarifas y de los impuestos directos y abogó por el libre comercio y la expropiación de los bienes de la Iglesia. Los conservadores expresaron su confianza en las tarifas altas, en el sistema centralista, el proteccionismo, el eventual establecimiento de una monarquía y el mantenimiento de una Iglesia vigorosa. Esto se puede entender, ya que este grupo formaba parte de la élite tradicional de la Ciudad de México y Veracruz y del gobierno español, eran empresarios algodoneros y poseían importantes nexos con la Iglesia.

12 AGNCDMX, Ramón de la Cueva, Notaría 169, Vol. 1008, 1848, f.101. Mentz, Los pioneros del imperialismo, p. 472.

${ }^{13}$ AGNCDMX, Ramón de la Cueva, Notaría 169, Vol. 1012, 1850, f. 123.

${ }^{14}$ APMCBFAHDL, Libro de Contabilidad, La Luz del Día, 1849, fs. s/n. En algunas partes del documento, se observa la acotación "pagado", en letras grandes encima de la cuenta. Asimismo, los tiempos de la liquidación de los adeudos fueron a corto plazo.

${ }^{15}$ APMCBFAHDL, Libro de Contabilidad, La Luz del Día, 1849, fs. $s / n$.

${ }^{16}$ Meyer, “Dos siglos, dos naciones”, p. 10. Lo que les permitió, décadas más tarde, obtener la fama de grandes y modernos almacenes que les pertenecían en la capital de la República, es el caso de El Palacio de Hierro, El Puerto de Liverpool, Las Fábricas Universales, El Centro Mercantil y La Francia Marítima, entre otros lugares -como 
Puebla- como lo han citado Leticia Gamboa Ojeda en Los barcelonnettes en México, miradas regionales, siglo XIX-XX y Sergio Valerio Ullúa, Almacenes comerciales franceses en Guadalajara, México (1850-1930).

17 APMCBFAHDL, Libro de Contabilidad, "La Luz del Día", 1849, fs. s/n.

18 AGNCDMX, Ramón de la Cueva, Notaria 169, Vol. 10121013, f. 167.

${ }^{19}$ Mentz, Los pioneros del imperialismo, p. 451.Los negocios de esta casa los llevaba en Hamburgo la firma Hanssen, la cual aparece en la Ciudad de México y en Bremen; los representaba la firma Philippi, presente - principalmente- en Mazatlán, por fusión con la casa de Melchers. La firma que continúa la actividad bancaria de la casa Uslar, Heymel y Cía., es el banco y casa de comercio Bonne, Ebert y Cía. que exporta importantes cantidades de plata, ligada con la fundición de plata Los Arcos. Durante el porfiriato, Bonne, Struck y Cía., principalmente esta última, mantendrá fuertes vínculos con acaudalados importadores de joyería de Frankfurt, la familia Diener, que tuvo en la Ciudad de México la joyería La Perla.

${ }^{20}$ Flores Caballero, Administración y política, p. 95.

${ }^{21}$ FUNDACIÓN CULTURAL ANTONIO HAGHENBECK Y DE LA LAMA, I.A.P. www.museoshaghenbck.mx

${ }^{22}$ AGNCDMX, Fondo Antiguo, Protocolos, Ramón de la Cueva, Notaria (169) Vol. 116, 1852, fs.996-997.

${ }^{23}$ Valerio Ulloa, Sergio, "Almacenes comerciales franceses en Guadalajara”, p. 70.

${ }^{24}$ AGNCDMX, Fondo Antiguo, Protocolos, Ramón de la Cueva, Notaría 169, vol. 116, 1852, f.998.

${ }^{25}$ Valerio Ulloa, Sergio, "Almacenes comerciales franceses en Guadalajara”, p. 76.

${ }^{26}$ De acuerdo a lo citado por Sergio Valerio, las redes sociales y económicas de paisanaje darán una fuerte cohesión dentro de los grupos de extranjeros y no dista de las presentadas en otros lugares de América Latina, que recurrieron a este tipo de prácticas para alcanzar su consolidación en las actividades económicas. Para argumentar este planteamiento, cita a algunos investigadores que llegan a esta 
conclusión: Valerio (Guadalajara), Gamboa (Puebla), Pérez (Distrito Federal), Barbero (Argentina), Betancourt y Krebs (Chile), Botero (Colombia) y Riviele (Perú).

${ }^{27}$ Mentz, Los pioneros del imperialismo, p.447.

${ }^{28}$ Valerio UlloA, Sergio, "Almacenes comerciales franceses en Guadalajara”, p. 74.

${ }^{29}$ APMCBFAHDL, Libro de contabilidad Carlos Haghenbeck y Cía. 1852-1856, f. 8.

${ }^{30}$ AGNCDMX, Francisco Miguel Calapiz, Notaria, 4479, 1852, Haghenbeck entregó un poder especial, el 1 de mayo de 1852, para hacer efectivo el cobro de deuda. Ramón de la Cueva, notaría 169, 51268, 16 de noviembre de 1854, Reconocimiento de deuda.

${ }^{31}$ APMCBFAHDL, Libro de contabilidad Carlos Haghenbeck y Cía, 1852-1856, f.8.

${ }^{32}$ APMCBFAHDL, Libro de contabilidad Carlos Haghenbeck y Cía, 1852-1856, fs. 11-12

${ }^{33}$ APMCBFAHDL, Libro de contabilidad Carlos Haghenbeck y Cía, 1852-, 1856 fs. 51, 52.

${ }^{34}$ APMCBFAHDL, Libro de contabilidad Carlos Haghenbeck y Cía. 1852-1856, f. 19.

${ }^{35}$ APMCBFAHDL, Libro de contabilidad Carlos Haghenbeck y Cía. 1852-1856, fs. 28,54, 102,

${ }^{36}$ Bernecker L, Alemania y México, p. 38.

37 AGNCDMX, Agustín Vera Sánchez, 46973, f. Libranza de la Carlos Haghenbeck y Cía. del 15 de mayo de1852. Crescencio Landgrave, 48478, f. Libranza de la Carlos Haghenbeck y Cía. del 24 de enero de 1853. Crescencio Landgrave, 48561, f. Libranza de la Carlos Haghenbeck y Cía. del 2 de julio de 1853. Crescencio Landgrave, 57824, f. Libranza de la Carlos Haghenbeck y Cía. 14 de abril de 1856.

38 Navarro Zamorano, Las letras de cambio. Libranzas, pp. 2235. Librancista era la persona que giraba el documento, libratorio el beneficiario y el mandatario el deudor.

39 Abascal Zamora, "Pasado, presente y futuro de los títulos valor", p. 9. Código de 1889, letra de cambio (artículo 451), libranza, vale o pagaré (artículo 546), cheque (artículo 553). 
${ }^{40}$ Quintana Adriano, Evolución histórica mercantil. Por comisión, se entiende la cantidad que se percibió por efectuar actividades comerciales bajo un cierto porcentaje sobre el importe de la operación. La consignación mercantil, hace alusión al contrato por el cual, una persona entrega y trasmite algún bien a otra persona denominada consignatario, para que pague un precio por ello en caso de venderlo en los términos establecidos y en caso de no ser comerciados se restituyan al propietario.

${ }^{41}$ Bernecker L, Alemania y México, pp. 54-59.

${ }^{42}$ APMCBFAHDL, Libro de Contabilidad Carlos Haghenbeck y Cía. 1852-1856, f. 26.

${ }^{43}$ APMCBFAHDL, Libro Almacén la Mina de Oro 1852-1854, f. 45 .

${ }^{44}$ AGNCMX, Crescencio Landgrave, Acta núm. 62696, 27 de marzo de 1857, Poder Especial, f. 32 . El caso de la calle Cadena número 21, según cuenta de la nueva firma, por la cantidad de 4,500.00 pesos, con fecha del 1 de agosto de 1852 , con un cobro del $1 \%$ mensual.

45 "La fundación Cultural Antonio Haghenbeck y de Lama, I.A.P, Diario Digital, Cultura UNAM, www.museosdemexico.org [Consulta 20 de agosto de 2014]

46 ORTEGA Ricardo, y Pérez Gallardo, Estudios genealógicos, p.48.

47 Siglo XIX, p.4. La nota continuó publicada en el mismo periódico, el 8, 20 y 22 de marzo de 1856. Esto puede indicar que muchos de sus acreedores y deudores no habían cumplido con sus compromisos hasta ese momento.

Fecha de Recepción: 16 mayo de 2018

Fecha de Aceptación: 02 de Diciembre 2018

VERSIÓn FINAL: 07 de diciembre de 2018 